\title{
DINÂMICA DA ÁGUA EM CAMBISSOLO HÚMICO SOB CULTIVO DO LINHO NO PLANALTO CATARINENSE
}

\author{
Water dynamics in Humic Cambisol under linseed tillage in the Santa Catarina Plateau \\ Carla Eloize Carducci'; ${ }^{1}$ Leosane Cristina Bosco ${ }^{2}$; Letícia Salvi Kohn ${ }^{3}$; Jânio dos Santos Barbosa ${ }^{4}$, Pedro Antônio \\ Namorato Benevenute ${ }^{5}$; Gustavo Henrique Mozzer Regazolli4

\begin{abstract}
${ }^{1}$ Professora Adjunto,Faculdade de Ciências Agrárias, Universidade Federal da Grande Dourados, Dourados-MS 2Professora Adjunto; Universidade Federal de Santa Catarina - Centro de Ciências Rurais, Curitibanos -SC.

${ }^{3}$ Acadêmico do curso de Agronomia; Universidade Federal de Santa Catarina - Centro de Ciências Rurais, Curitibanos-SC

${ }^{4}$ Acadêmico do curso de Eng. Florestal; Universidade Federal de Santa Catarina - Centro de Ciências Rurais, Curitibanos-SC ${ }^{5}$ Acadêmico do curso de Agronomia; Departamento de Ciência do Solo; Universidade Federal de Lavras, Lavras-MG
\end{abstract}

Artigo enviado em 21/12/2016, aceito em 13/03/2017 e publicado em 11/04/2017.

\begin{abstract}
RESUMO: Os solos, de acordo com suas variações pedogenéticas, e associado a interface climática, apresentam comportamento diferenciado quanto à dinâmica da água no solo. $\mathrm{O}$ trabalho teve por objetivo distinguir ambientes mais favoráveis ao desenvolvimento de diferentes variedades de linho quanto ao potencial físico-hídrico do solo. O experimento foi implantado em um Cambissolo Húmico, em Curitibanos, SC. Foram utilizados linho com sementes cor marrom e amarelo-dourada semeados em agosto de 2014 e 2015. Foram determinados os atributos físicos e hídricos do solo como granulometria, densidade do solo, capacidade de campo, ponto de murcha permanente, capacidade de água disponível, monitoramento de umidade e armazenamento da água no solo e balanço hídrico da cultura em 2014 e 2015. Foi determinado também o conteúdo de carbono orgânico total. Nos dois ambientes edafoclimáticos (ano 2014 e 2015) monitorados, as condições físico-hídricas do Cambissolo para o cultivo do linho favoreceram o fornecimento de água para a planta, com pequenas variações no armazenamento de água no solo decorrente das alterações meteorológicas. Os períodos de menor conteúdo de água coincidiram com a primeira fase vegetativa do linho em ambas as variedades. No ambiente edofoclimático de 2015 o conteúdo de água no solo permaneceu acima da capacidade de água disponível com balanço hídrico registrando excessos de água no solo.
\end{abstract}

Palavras-chave: Linum usitatissimum L., armazenamento de água, balanço hídrico, solos orgânicos

ABSTRACT: The soils, according to their pedogenetic variations, and associated to the climatic interface, present different behavior regarding the water dynamics and storage. The study aimed to distinguish more favorable environment for the development of different varieties of linseed as the soil physical- hydric potential. The experiment was implanted in an Humic Cambisol, in Curitibanos, SC. Were used linseed brown and yellow-gold sown in August 2014 and 2015. Soil physical and hydric attributes were determined as, granulometry, soil bulk density, field capacity, permanent wilting point, available water capacity and water storage beyond moisture monitoring during the crop cycle during 2014 and 2015, as well as the water balance of the crop. The total organic carbon were also determined. In the two years of monitoring of the physical and water conditions of the Humic Cambisol for linseed cultivation, it was evident the good water supply to the plant, with small variations in the soil water storage due to the meteorological changes. The periods of lower water content coincided with the first vegetative phase of the linseed. In the year of 2015 the water content in the soil remained above the available water capacity with water balance recording excess of water in the soil.

Key words: Linum usitatissimum L., water storage, water balance, organic soils 


\section{INTRODUÇÃO}

A disponibilidade de água é um dos principais fatores físicos que influenciam diretamente $\mathrm{O}$ desenvolvimento e a produção das culturas agrícolas. A água oriunda das precipitações varia em intensidade e distribuição, e assim o solo possibilita seu armazenamento, retenção e disponibilidade conforme a ocorrência de chuvas. Entretanto, esse fornecimento de água do solo para a planta, é resultante do efeito combinado de vários fatores físicos e químicos, a exemplo da granulometria, estrutura, mineralogia e conteúdo de matéria orgânica, bem como a cobertura vegetal sobre o solo. Isto evidencia a estreita relação das práticas de uso e manejo com os fatores que determinam tanto o armazenamento quanto a disponibilidade da água no solo (REICHERT et al., 2011; SERAFIM et al., 2013).

Para obter elevadas produtividades é essencial considerar o conteúdo de água do solo que proporciona um bom desenvolvimento das plantas, não apenas pela recarga hídrica proveniente da precipitação, mas também pela movimentação e absorção de nutrientes e pela influência na atividade biológica (COSMO et al., 2014).

O monitoramento hídrico do solo e da cultura é de grande importância, devido a relação direta nas interfaces solo-água-planta onde, com o armazenamento de água no solo determina-se a quantidade de água que permanece ao alcance do sistema radicular, e o balanço hídrico da cultura avalia a intensidade das saídas e entradas de água, por meio de parâmetros meteorológicos (precipitação e evapotranspiração), fenológicos (estádios de desenvolvimento) e físicos do solo (capacidade de água disponível), o que permite definir com melhor precisão os períodos mais prováveis de déficit hídrico para a cultura e, assim, estabelecer um manejo agrícola adequado que visa a conservação do solo e da água (SILVA et al., 2014; CASA et al., 1999).

O uso de espécies mais resistentes aos déficits hídricos tem sido cada vez mais estudadas e empregadas na produção agrícola brasileira. Para a região sul do país onde as estações são bem definidas ao longo do ano, há o uso de espécies mais exigentes em água, embora alterações climáticas que vem ocorrendo nos últimos anos, indicam a necessidade de uso de espécies que utilizam a água do solo com melhor eficiência. Neste contexto a cultura do linho, espécie milenar e rústica, porém que está sendo utilizada como cultura de inverno tanto para produção de cobertura vegetal como para a produção da linhaça (semente) em rotação com as culturas de verão.

O linho (Linum usitatissimum L.) é uma planta oleaginosa, que possui duas variedades de coloração de sementes uma de cor marrom e outra de amarelodourado. Estas não se diferem em sua composição, porém apresentam temperaturas diferenciadas para atingir a produção final, a variedade amarela-dourada, produz melhor em regiões mais frias, e a marrom se adapta a temperaturas mais amenas $\left(20^{\circ} \mathrm{C}\right)$. De acordo com Bassegio et al. (2012), por exigir baixas temperaturas na floração, o linho de sementes marrons se adapta a regiões de clima úmido e temperatura amena, como na região Sul do Brasil e a dourada se adapta melhor a países mais frios como o Canadá, que é o principal produtor mundial.

Os solos, de acordo com suas variações pedogenéticas, e associado a interface climática, apresentam comportamento diferenciado quanto à dinâmica e ao armazenamento de água. Neste sentido, desenvolveu-se este trabalho com o objetivo de distinguir ambientes mais favoráveis ao desenvolvimento de variedades de linhaça quanto ao potencial físico-hídrico do solo.

\section{MATERIAL E MÉTODOS}

\section{Descrição da área de estudo}

O estudo foi conduzido na área experimental da Universidade Federal de Santa Catarina em Curitibanos, SC (27¹6'58'S e 50³5'04'W) a $978 \mathrm{~m}$ de altitude. O clima da região é do tipo $\mathrm{Cfb}$ subtropical úmido com verões amenos, sendo a precipitação média anual em torno de $1.480 \mathrm{~mm}$ (EMBRAPA, 2011).

O solo sob o cultivo das duas variedades de linhaça foi classificado como Cambissolo Húmico Háplico, conforme Santos et al. (2013), originado do basalto com textura muito argilosa, na camada de 0 0,10 m 648, 291 e $61 \mathrm{~g} \mathrm{~kg}^{-1}$ e de 0,10-0,20 m 656, 268 e $76 \mathrm{~g} \mathrm{~kg}-1$ de argila, silte e areia respectivamente.

Análises químicas para caracterização da fertilidade do solo nos anos de 2014 (antecedente a implantação do linho) e 2015 foram realizadas na camada de 0-0,20 $\mathrm{m}$ de profundidade (Tabela 1$)$. 
Tabela 1. Análises químicas do Cambissolo Húmico na camada de 0-0,20 m para os dois anos de cultivo.

\begin{tabular}{|c|c|c|c|c|c|c|c|c|c|c|c|c|c|c|}
\hline \multirow{2}{*}{ Ano } & \multirow{2}{*}{$\mathrm{pH}\left(\mathrm{H}_{2} \mathrm{O}\right)$} & SB & $\mathrm{t}$ & $\mathrm{T}$ & $\mathrm{Al}$ & $\mathrm{H}+\mathrm{Al}$ & $\mathrm{Ca}$ & $\mathrm{Mg}$ & & $\mathrm{m}$ & $\mathrm{K}$ & $\mathrm{P}$ & $\mathrm{Na}$ & \\
\hline & & \multicolumn{7}{|c|}{$\ldots \ldots \ldots \ldots \mathrm{cmol}_{\mathrm{c}} \mathrm{dm}^{-3} \ldots \ldots \ldots \ldots \ldots \ldots$} & \multicolumn{2}{|c|}{$\ldots \ldots \% \ldots \ldots$} & \multicolumn{3}{|c|}{$\ldots . . . \mathrm{mg} \mathrm{dm} \mathrm{dm}^{-3} \ldots .}$. & $m g L^{-1}$ \\
\hline 2014 & 6 & 14,5 & 14,7 & 19,7 & 0,1 & 5,05 & 8,4 & 6 & 74,3 & 0,7 & 92 & 3,5 & 0 & 4,31 \\
\hline 2015 & 5,1 & 8,6 & 8,8 & 16,1 & 0,2 & 7,45 & 4,1 & 4,2 & 53,6 & 2,3 & 116 & 3,5 & 0 & 6,29 \\
\hline
\end{tabular}

A implantação da cultura ocorreu em agosto de 2014. Primeiramente foi realizado a aração em área total, para eliminação de canteiros olerícolas préexistentes no local do experimento, nesse procedimento o arado reversível com 3 discos de 28 " foi passado em cada faixa de ação, aproximadamente quatro vezes, até a homogeneização da área e em seguida foi realizado o nivelamento para uniformização da superfície do solo. Em 2015, realizou-se semeadura sem revolvimento do solo.

A semeadura nos anos de 2014 e 2015 ocorreu de forma manual e realizada com duas variedades de linhaça, uma com sementes de cor marrom e outra amarelo-dourada, sendo o ciclo da cultura de aproximadamente 120 dias. A cultura foi conduzida em sistema de cultivo mínimo e princípios agroecológicos (não uso de defensivos agrícolas e adubos químicos), em uma área de $150 \mathrm{~m}^{2}$, sendo dividida em três blocos de $50 \mathrm{~m}^{2}$ e as parcelas foram compostas pelas variedades. O espaçamento de $0,45 \mathrm{~m}$ entrelinhas e $0,05 \mathrm{~m}$ entre plantas foi utilizado. Até a colheita da linhaça não foi realizado nenhum tipo de trato cultural (pulverizações, correções e adubação foliar).

\section{Perfil cultural e Amostragem do solo}

Foram abertas três trincheiras aleatórias em cada tratamento, para avaliação do perfil cultural
(TAVARES FILHO et al. 1999). Por meio dessa técnica obtiveram-se os critérios de descrição dos modos de organização do solo, sendo utilizadas as seguintes simbologias: Nível $1-\mathrm{AM}=$ Volume de solo visualmente alterado pelo manejo, isto é, pelo maquinário e pelas raízes; NAM = Volume de solo visualmente não alterado pelo manejo; $\mathrm{L}=$ Volume de solo livre, solto, constituído por terra fina, agregados e torrões de tamanhos variados (de 0 a $10 \mathrm{~cm}$ ) sem nenhuma coesão; Nível 2 - do estado interno dos torrões presentes nos diferentes modos de organização do volume de solo antropizado: $\mu=$ Agregado não compactado; $\Delta=$ Agregado compactado; $\mu \Delta / \Delta \mu=$ Agregado em algum estádio de compactação, ou seja, a) $\mu \Delta=$ agregados que estão em processo de compactação, mas que ainda guardam predominantemente as características do estado não compacto $(\mu)$ sobre as características do estado compacto $(\Delta)$; b) $\Delta \mu=$ agregados que estão fortemente compactos.

Conjuntamente a análise do perfil cultural foi utilizada a análise visual da estrutura (VESS) para identificação da qualidade estrutural do solo proposta por Ball et al. (2007), onde se pontua a qualidade do agregado por meio de notas como: Qe1 = Friável (estrutura boa); Qe2 = Intacto; Qe3 = Firme; Qe4 Compacto; Qe5 = Muito compacto (estrutura pobre). Dessa forma definem-se cinco escores visuais $(\mathrm{Ev})$ para a classificação da qualidade: de $\mathrm{Ev}=1$ (melhor qualidade estrutural) a $E v=5$ (degradação estrutural) (Tabela 2).

Tabela 2. Descrição do perfil cultural e da análise visual da estrutura do solo (VESS) com os valores do Score Visual (EV) e perfil cultural (PF) para o Cambissolo Húmico cultivado sob duas variedades da linhaça.

\begin{tabular}{llllll}
\hline \multirow{2}{*}{ Marriedades } & Profundidade & VESS & EV(1) & Porosidade visível & PF \\
\cline { 2 - 5 } & $0,0-0,10$ & Q3/Firme & 2,40 & pouco & AML $\mu \mu$ \\
& $0,10-0,20$ & Q2/Intacto & & alta & AML $\mu$ \\
Dourada & $0,0-0,10$ & & & AML $\mu$ \\
& $0,10-0,20$ & Q1/Friável & 2,35 & alta & AML $\mu \Delta$ \\
\hline
\end{tabular}

(1) Cálculo de EV (escore visual) realizado de acordo com a equação: [nota Qe*camada avaliada $(\mathrm{cm}) /$ profundidade total $(\mathrm{cm})]+[$ nota Qe*camada avaliada $(\mathrm{cm}) /$ profundidade total $(\mathrm{cm})]$ proposta por Ball et al.(2007), valores médios de quatro repetições. 
Através das análises visuais identificaram-se duas camadas de solo com estrutura contrastante a 0,0 $0,10 \mathrm{~m}$ e $0,10-0,20 \mathrm{~m}$ e maior concentração do sistema radicular (KOHN et al., 2016) onde foram coletadas amostras de solo com estrutura preservada em anéis volumétricos com dimensão de $0,06 \mathrm{~m}$ de diâmetro e $0,025 \mathrm{~m}$ de altura e amostras com estrutura alterada, ambas em triplicata logo após a colheita da cultura do linho em 2014 e 2015.

\section{Análises físicas e químicas}

Para o ano de 2014 com as amostras alteradas foram determinadas a granulometria do solo pelo método da pipeta pelo emprego de agitação rápida (10000 rpm) da suspensão do solo usando $\mathrm{NaOH}$ $1 \mathrm{~mol} \mathrm{~L}^{-1}$ em contato com a amostra durante $24 \mathrm{~h}$, como dispersante químico (Embrapa 2011). Procedeuse à quantificação das partículas de areia $(2,00-0,05$ $\mathrm{mm})$, por tamisagem; de argila $(<0,002 \mathrm{~mm})$, pelo método da pipeta; e de silte $(0,05-0,002 \mathrm{~mm})$, determinada pela diferença entre o teor total da amostra de solo e os teores de areia e argila.

No ano de 2014 e 2015 foram determinadas a densidade do solo pelo método do anel volumétrico encaminhados a estufa a $105-110^{\circ} \mathrm{C}$ por $48 \mathrm{~h}$, além da porosidade total e distribuição de poros conforme Embrapa (2011).

O conteúdo de carbono orgânico foram calculados pela equação: $\mathrm{Mo}=\mathrm{C} * 1,724$, onde: $\mathrm{Mo}=$ matéria orgânica $\left(\mathrm{g} \mathrm{kg}^{-1}\right)$; C= é o carbono orgânico ( $\mathrm{g}$ $\left.\mathrm{kg}^{-1}\right)$ e 1,724 é um fator utilizado em virtude de se admitir que, na composição média do húmus, o carbono participa com 58\% obtidos pelo método da oxidação por dicromato de potássio e a titulação com sulfato ferroso amoniacal (método Walkley e Black) descrito em Embrapa (2011).

Determinou-se também o $\mathrm{pH}$ em $\mathrm{H}_{2} \mathrm{O}$ e o $\mathrm{pH}$ em $\mathrm{KCl}$ (os quais avaliam a acidez ativa e a acidez trocável, respectivamente), para estimar o balanço de carga líquida do solo $(\Delta \mathrm{pH})$ de acordo com a equação: $\Delta \mathrm{pH}=\mathrm{pH}_{\mathrm{KCl}}-\mathrm{pH}_{\mathrm{H} 2 \mathrm{O}}$ bem como, foi estimado o ponto de carga zero (PCZ), conforme a equação: PCZ $=2 \mathrm{pH}_{\mathrm{KCl}}-\mathrm{pH}_{\mathrm{H} 2 \mathrm{O}}$ proposta por Uehara and Gillman, (1980). Ambas as análises determinadas em triplicata.

\section{Análises hídricas monitoramento, armazenamento e disponibilidade de água}

O monitoramento do conteúdo de água no solo foi determinado pelo método gravimétrico, onde foram coletadas amostras de solo na entrelinha da cultura, no ano de 2014 na profundidade de $0-0,10 \mathrm{~m}$ e ano de $2015 \mathrm{em}$ duas profundidades $0-0,10 \mathrm{~m}$ e 0,10 -
$0,20 \mathrm{~m}$ para cada variedade de linhaça, durante todo o ciclo da cultura $(\approx 120$ dias), com o auxilio do trado holandês, realizadas semanalmente e, a cada nova incidência pluviométrica. Logo em seguida, as amostras eram encaminhadas a estufa a $105-110^{\circ} \mathrm{C}$ para secagem do solo por $24 \mathrm{~h}$ para então se determinar o conteúdo de água no solo (SERAFIM et al., 2013).

As amostras com estrutura preservada foram submetidas a saturação gradual sendo posteriormente submetidas às tensões de $6 \mathrm{kPa}$ e $10 \mathrm{kPa}$ nos funis de Buchner e $1500 \mathrm{kPa}$ em câmaras extratoras de Richards para determinação da capacidade de campo (CC) e ponto de murcha permanente (PMP), respectivamente. Posteriormente, foi determinada a capacidade de água disponível (CAD) do solo em estudo, que é calculada pela diferença entre o conteúdo de água na CC e no PMP. Foi determinado também o armazenamento de água no solo na faixa de exploração do sistema radicular da linhaça $(0-0,20 \mathrm{~m})$, a partir da equação: , onde: $\mathrm{Al}=A l=\sum_{i=1}^{n} \theta$ armazenamento é igual ao somatório do conteúdo de água no solo (REICHARDT; TIMM, 2008).

\section{Balanço hídrico}

O balanço hídrico sequencial durante os períodos experimentais foi calculado de acordo com o método de Thornthwaite-Mather (1955), elaborado para o acompanhamento do armazenamento de água no solo em tempo real. Dados meteorológicos de radiação solar, temperatura do ar, umidade do ar, velocidade do vento e precipitação pluvial foram obtidos de estação meteorológica do Instituto Nacional de Meteorologia (INMET), instalada em Curitibanos, SC. Esses dados foram utilizados para determinação da evapotranspiração de referência (ETo) conforme estabelece o método de PenmanMonteith. A evapotranspiração de cultura (ETc) foi determinada considerando o coeficiente de cultura (Kc) médio do linho 1,05 (ALLEN et al. 1998). A capacidade de água disponível (CAD) foi determinada nesse estudo conforme metodologia descrita acima.

\section{Análises estatísticas}

O delineamento experimental foi em blocos ao acaso. Com a finalidade de descrever a variabilidade observada e indicar a imprecisão associada à estimativa dos dados referentes aos atributos hídricos do solo foi utilizada a média e o erro padrão da média. 


\section{RESULTADOS E DISCUSSÕES}

O Cambissolo Húmico, sob cultivo das duas variedades de linhaça, apresentou diferenças nos atributos físicos e hídricos ao longo do tempo avaliado (ano 2014 e 2015). O alto conteúdo de matéria orgânica encontrada nas camadas de solo avaliadas (Figura 1) se deve as condições climáticas da região, caracterizada pelas baixas temperaturas e alta umidade relativa do ar, propícias ao acúmulo de material orgânico no solo e, consequentemente, o carbono orgânico total (COT), sendo comuns solos com horizontes superficiais do tipo A húmico ou hísticos na Mesorregião Serrana.

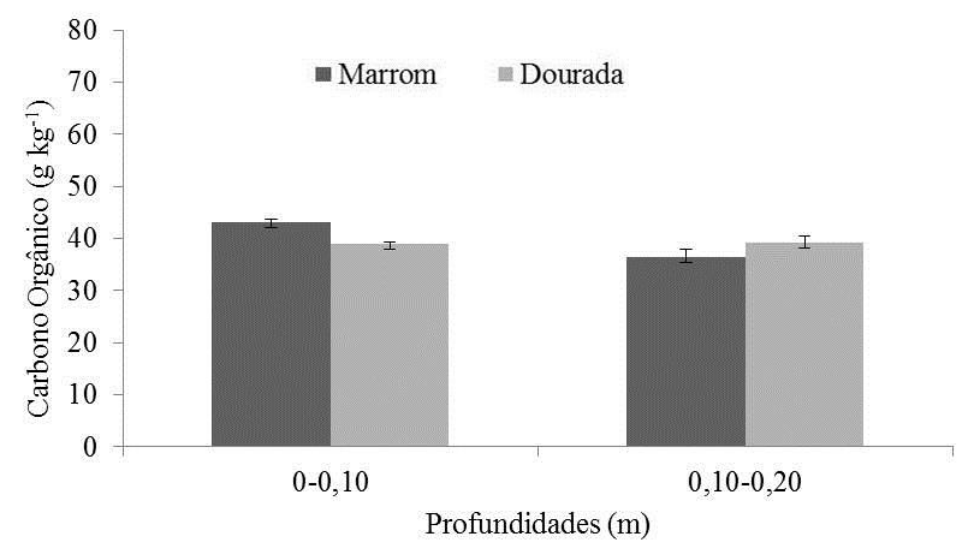

Figura 1. Valores médios de carbono orgânico total (COT) em duas camadas: 0-0,10 e 0,10-0,20 m. Barras indicam o erro padrão da média.

Essa alta concentração de COT promove melhorias das condições físico-hídricas. Alguns autores relacionam o aumento do carbono orgânico a um aumento da porosidade do solo, e consequentemente, maior conteúdo de água principalmente nas camadas superficiais (SILVA et al., 2013; COSTA et al., 2013).

Os coloides orgânicos além de reter uma grande quantidade de água, favorecem a formação de carga líquida negativa na superfície dos complexos sortivos devido à adsorção de ácidos orgânicos pelos coloides minerais, incrementando posteriormente a capacidade do solo em trocar cátions, como é o caso do Cambissolo em estudo, que apresentou seu ponto de carga zero (PCZ) equivalente ao da matéria orgânica, considerado então um solo eletronegativo (Tabela 3). Esse efeito da matéria orgânica no aumento das cargas ocorre especialmente, em solos que apresentam dependência do $\mathrm{pH}$ para formação destas, caso típico dos solos brasileiros (BENITES et al., 1998; ALBUQUERQUE et al., 2003).

Tabela 3. Valores médios da eletroquímica do Cambissolo Húmico sob cultivo da linhaça (Linum Usitatissimum L) em duas camadas de estudo.

\begin{tabular}{ccccc}
\hline & $\mathrm{pH}-$ água & $\mathrm{pH}-\mathrm{KCl}$ & $\Delta \mathrm{pH}$ & $\mathrm{PCZ}$ \\
\hline Variedades & & $0-0,10 \mathrm{~m}$ & \\
\hline Marrom & 6,38 & 5,34 & $-1,04$ & 4,3 \\
Dourada & 7,12 & 4,94 & $-2,18$ & 2,76 \\
\cline { 2 - 5 } & & $0,10-0,20 \mathrm{~m}$ & & 2,90 \\
Marrom & 6,68 & 4,79 & $-1,89$ & 3,14 \\
Dourada & 6,58 & 4,86 & $-1,72$ & \\
\hline
\end{tabular}


Nos anos de monitoramento do experimento pode-se observar que houve mudanças na organização estrutural desses solos observadas tanto na análise visual da estrutura do solo (Tabela 2), e confirmada pelos atributos físicos (Tabela 4), como a elevação nos valores de densidade do solo (Ds) nas duas camadas avaliadas, porém sem prejuízo ao fluxo de gases no solo, pois os macroporos (Ma) ficaram acima do valor considerado crítico $\left(0,10 \quad \mathrm{~cm}^{3} \mathrm{~cm}^{-3}\right)$ para o desenvolvimento das raízes, levando em consideração o processo respiratório necessário ao metabolismo da planta e dos micro-organismos presentes no solo (COLLARES et al., 2008).

Os microporos (Mi) influenciam na retenção e armazenamento de água nesse solo, sendo que parte dessa água será disponibilizada gradativamente para a planta, assim como, ao observar os valores de capacidade de campo (CC) e ponto de murcha permanente (PMP) pode-se verificar que o solo retém uma grande quantidade de água, porém o valor de aproximadamente $40 \%$ de água retida no PMP é um valor indisponível para as planta por estar fortemente retida nos microporos (OLIVEIRA et al., 2004; CARDUCCI et al., 2011).

Apesar de identificadas alterações no modo de organização dos agregados do Cambissolo Húmico pela análise visual da estrutura (Tabela 2) devido à presença de agregados, às vezes mais compactos ou mais friáveis, não houve impedimentos físicos crítico ao desenvolvimento das raízes do linho.

Com a determinação da capacidade de água disponível (CAD) foi possível verificar que o solo em estudo disponibiliza uma boa quantidade de água para as culturas ao longo do perfil (Tabela 4), o que é explicado pela presença do COT em grande quantidade nesse solo e pode chegar a reter de 2 a 3 vezes mais água em relação ao seu peso na camada superficial (ANDRADE et al. 2010), na camada mais profunda a CAD reduziu em consequência do aumento da Ds (Figura 1).

Tabela 4. Valores médios dos atributos físicos e hídricos do Cambissolo Húmico cultivado com linhaça em dois anos e duas camadas de estudo.

\begin{tabular}{|c|c|c|c|c|c|c|c|}
\hline \multirow{2}{*}{ Ano } & $\mathrm{Ds}^{(1)}$ & $\mathrm{PT}^{(2)}$ & $\mathrm{Mi}^{(3)}$ & $\mathrm{Ma}^{(4)}$ & $\mathrm{CC}^{(5)}$ & $\mathrm{PMP}^{(6)}$ & \multirow[t]{2}{*}{$\mathrm{CAD}^{(7)}$} \\
\hline & $\mathrm{Mg} \mathrm{m}^{-3}$ & \multicolumn{5}{|c|}{ (2) } & \\
\hline & \multicolumn{7}{|c|}{$0-0,10 \mathrm{~m}$} \\
\hline 2014 & $1,19( \pm 0,022)$ & $0,78( \pm 0,008)$ & $0,58( \pm 0,062)$ & $0,19( \pm 0,059)$ & $0,58( \pm 0,062)$ & $0,40( \pm 0,016)$ & $0,18( \pm 0,049)$ \\
\hline \multirow[t]{2}{*}{2015} & $1,92( \pm 0,177)$ & $0,58( \pm 0,053)$ & $0,45( \pm 0,023)$ & $0,13( \pm 0,048)$ & $0,44( \pm 0,025)$ & $0,37( \pm 0,021)$ & $0,07( \pm 0,011)$ \\
\hline & & & & $0,10-0,20 \mathrm{~m}$ & & & \\
\hline 2014 & $1,38( \pm 0,045)$ & $0,71( \pm 0,017)$ & $0,47( \pm 0,036)$ & $0,23( \pm 0,048)$ & $0,47( \pm 0,036)$ & $0,37( \pm 0,023)$ & $0,10( \pm 0,019)$ \\
\hline 2015 & $1,80( \pm 0,171)$ & $0,62( \pm 0,063)$ & $0,48( \pm 0,035)$ & $0,14( \pm 0,049)$ & $0,48( \pm 0,035)$ & $0,42( \pm 0,031)$ & $0,06( \pm 0,009)$ \\
\hline
\end{tabular}

(1)Ds: densidade global do solo; (2)PT: porosidade total; (3)MI: microporos; (4)Ma: macroporos; (5)CC: capacidade de campo a -6 kPa; () PMP: ponto de murcha permanente a $-1500 \mathrm{kPa}$; (7) $\mathrm{CAD}$ : capacidade de água disponível $[\mathrm{CAD}=6 \mathrm{kPa}-1500 \mathrm{kPa}$. Valores entre parênteses se referem ao erro padrão da média.

O monitoramento de umidade apresentou diferenças de um ano para o outro de acordo com a incidência pluviométrica (Figura 2), porém ambas as variedades tiveram desenvolvimento satisfatório ao longo do ciclo de cultivo, não ocorrendo déficits hídricos nos períodos de maior exigência de água pela planta (florescimento-enchimento de cápsulas) (COSMO et al., 2014; CASA et al., 1999) (Figura 4). 

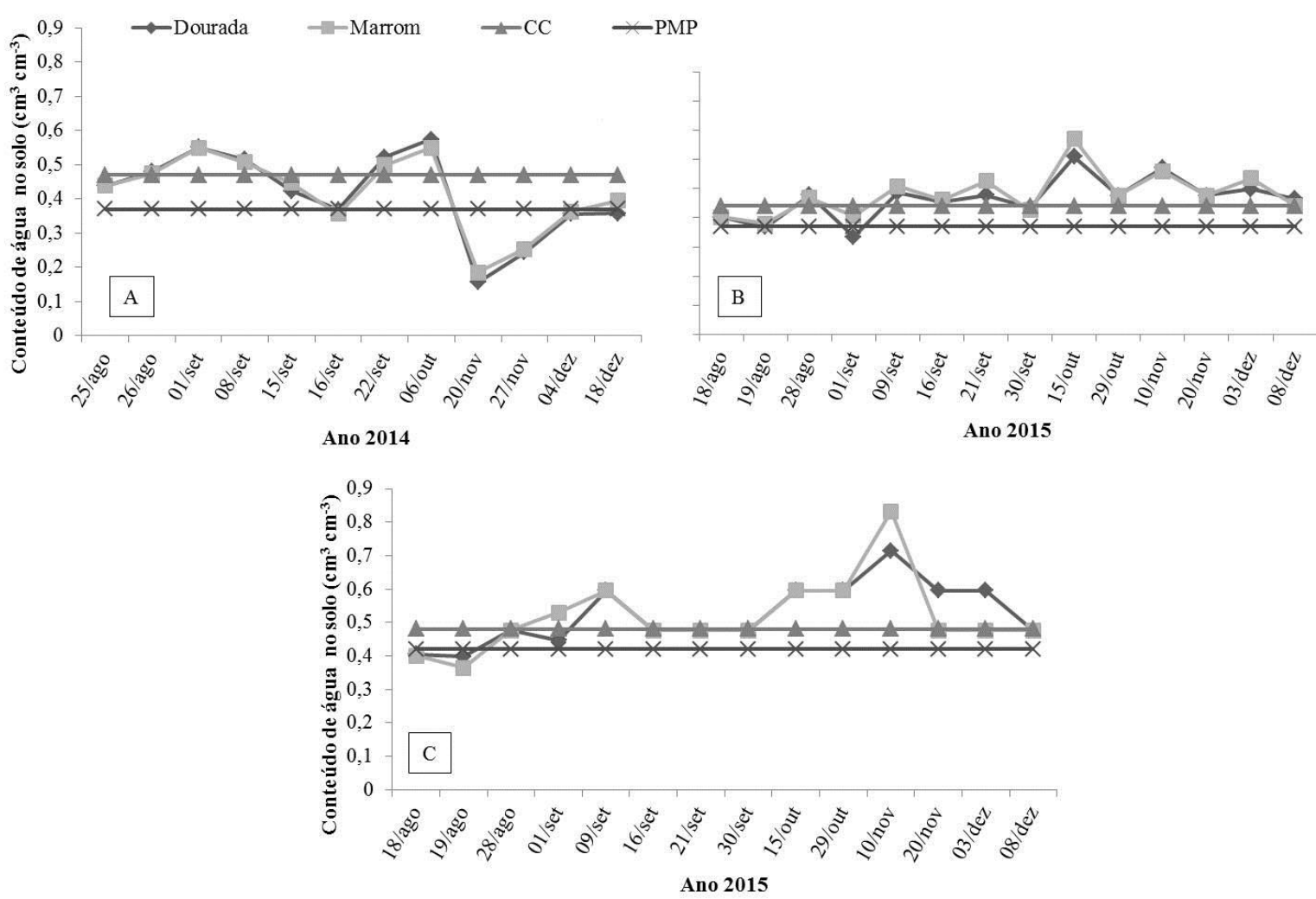

Figura 2. Valores médios do monitoramento do conteúdo de água no Cambissolo Húmico sob cultivo de linhaça nos anos de 2014 e 2015 ao longo do ciclo da cultura. A e B correspondem a 0-0,10m e C a 0,10-0,20 m.

No ano de 2014 houve um decréscimo no conteúdo de água no solo no mês de setembrooutubro que antecedeu o florescimento (Figura 2) e, favoreceu o potencial metabólico da planta para a formação de cápsulas após o florescimento (CASA et al., 1999). No mês de novembro o conteúdo de água do solo ficou novamente abaixo da CC, o que favoreceu o estágio final de maturação e início de colheita da cultura, favorecendo a produtividade das duas variedades que foram de $745 \mathrm{~kg} \mathrm{ha}^{-1}$ para a linhaça dourado a $800 \mathrm{~kg} \mathrm{ha}{ }^{-1}$ para a linhaça marrom (KOHN et al., 2016). Essa maior produtividade da linhaça marrom pode ser justificado, pela sua melhor adaptabilidade às condições climáticas da Mesorregião Serrana (clima $\mathrm{Cfb}$ ), visto que a linhaça dourada precisa de maior exposição a baixas temperaturas para ter melhor desempenho em produção (CASA et al. 1999).

Esse fato não ocorreu em 2015, devido o maior fornecimento de água nesse mesmo período, o solo permaneceu com o conteúdo de água acima da CAD nos meses de outubro e novembro, devido ao fenômeno "El Niño" que promoveu a maior ocorrência e intensidade de chuva. Essa alteração climática contribui com a formação de um menor número de cápsulas por planta, bem como o aparecimento de novos ramos, reduzindo então a produtividade da cultura que ficou em torno de $500 \mathrm{~kg}$ $\mathrm{ha}^{-1}$ para ambas as variedades (544 $\mathrm{kg} \mathrm{ha}^{-1}$ linhaça marrom e $514 \mathrm{~kg} \mathrm{ha}^{-1}$ linhaça dourada) (KOHN et al., 2016).

Além do alto conteúdo de MOS e COT (Figura 1) que favorece a retenção de água no solo é importante destacar que no ano de 2015 ocorreu o fenômeno "El Niño", sendo caracterizado por uma anomalia climática, que permite o aumento da precipitação na região Sul e, sobretudo da intensidade do fenômeno. O "El Niño" teve grande influência no Sul do Brasil, o que contribui com o aumento dos índices pluviométricos (Figura 4), como o ocorrido na região desse estudo.

Dessa forma foi possível verificar que as plantas de linhaça dourada e marrom obtiveram um adequado desenvolvimento ao longo do cultivo, não ocorrendo déficits hídricos nos períodos de maior exigência em água pela planta (enchimento de grãos), identificado pelo monitoramento do conteúdo de água no solo e pelo armazenamento (Figuras 2 e 3 ). 
Houve pequena variação no armazenamento no ano de 2014 na profundidade de 0-0,10 $\mathrm{m}$ no mês de novembro (4 $\mathrm{mm}$ ) que coincidiu com as menores precipitações (Figura 4). No ano de 2015 o armazenamento de água foi superior a $7 \mathrm{~mm}$ em todos os meses referentes ao ciclo fenológico do linho, chegando a $18 \mathrm{~mm}$ de água armazenada na profundidade de 0,10-0,20 $\mathrm{m}$ no mês de novembro (Figura 3).
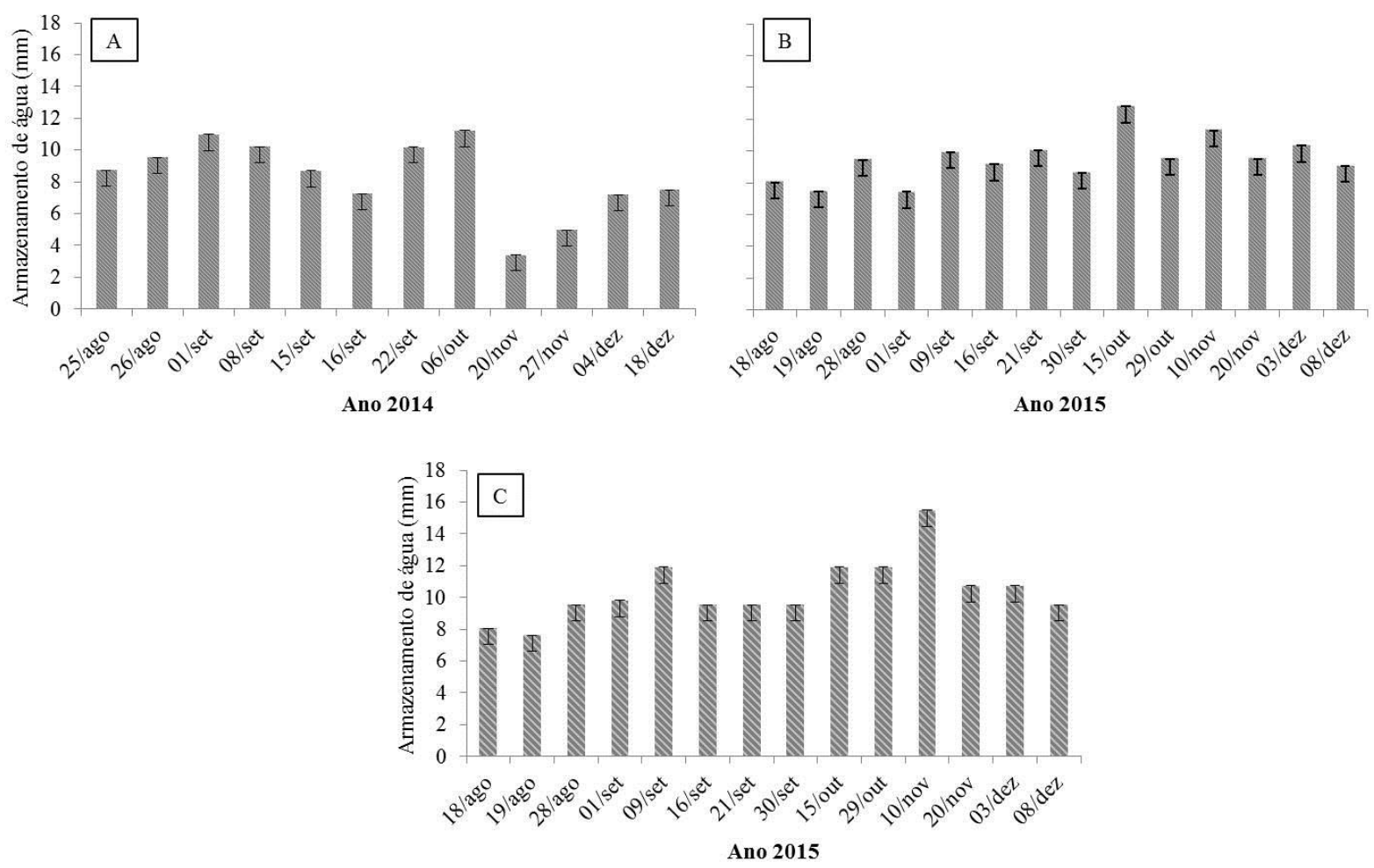

Figura 3. Valores médios de armazenamento da água no Cambissolo Húmico sob cultivo de linhaça nos anos de 2014 e 2015 ao longo do ciclo da cultura. A e B correspondem a 0-0,10m e C a 0,10-0,20 m.

Sabe-se que a produção máxima de uma cultura é determinada pela associação entre as condições edafoclimáticas e a genética da planta, nesse sentido quanto melhor for o ambiente de crescimento das raízes, melhor será a aquisição de nutrientes e absorção de água do solo pelas plantas (SERAFIM et al., 2013) o que pode ser observado pelos valores do armazenamento de água que ficaram dentro dos limites considerados ideais para o desenvolvimento das culturas (SILVA et al., 2005).

É importante ressaltar que esses altos valores de armazenamento de água no Cambissolo Húmico são devido a sua relação direta da retenção de água com os altos conteúdos de COT e argila (Figura 1, Tabela 1) associada a uma boa qualidade estrutural do solo como encontrado nesse estudo (COSTA et al., 2013; SILVA et al., 2005).
A dinâmica da água no solo investigada pelo monitoramento e armazenamento associados às alterações estruturais podem então validar o balanço hídrico da cultura, onde são registrados os excessos e déficits de água conforme as exigências do linho em estudo (Figura 4). Além disso, de acordo com Moreira et al. (2014), os componentes do balanço hídrico podem variar com as alterações estruturais dos solos e com o tempo. 

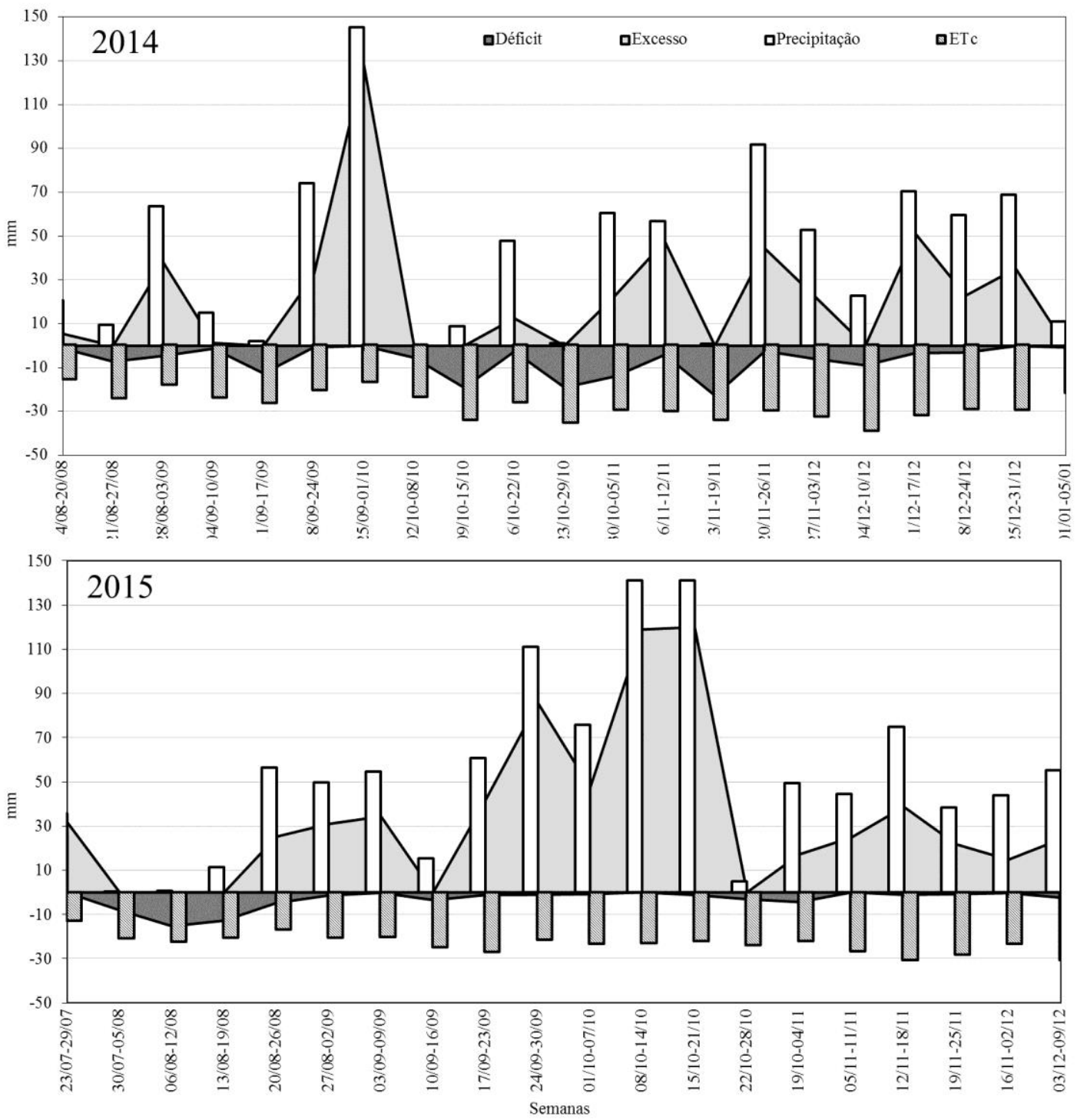

Figura 4. Balanço hídrico da cultura da linhaça nos anos de 2014 e 2015, considerando déficit e excesso de água no solo, precipitação pluvial semanal e evapotranspiração da cultura (ETc).

$\mathrm{Na}$ avaliação do balanço hídrico foi possível observar que em 2014 o déficit hídrico acompanhou as menores precipitações e maiores valores de evapotranspiração corroborando com Silva et al. (2014), porém houve uma melhor distribuição da água armazenada ao longo do ciclo do linho (Figura 3) devido as boas condições físicas do solo (Tabela 1) que contribuíram para uma adequada disponibilidade de água para as plantas. Os déficits hídricos identificados no balanço hídrico ocorreram em fases fenológicas consideradas de pouca exigência da planta por água (período vegetativo) (Figura 4). De forma geral houve maior disponibilidade de água em relação aos déficits do ano 2014 (Figura 3, Tabela 1).

Por outro lado, fato inverso foi observado em 2015, onde foram registrados muitos períodos de excesso de água durante o ciclo do linho, o que prejudicou a fase de formação de cápsulas e enchimento de grãos (novembro), reduzindo a produtividade da linhaça para ambas as variedades. Kohn et al. (2016), observou que a baixa produtividade em 2015 ocorreu em função da maior concentração das raízes do linho na camada superficial do solo $(0-0,10 \mathrm{~m})$ promovida pela maior oferta de água (Figura 3 e 4) e, consequentemente 
menor exploração do solo pelo sistema radicular em busca de nutrientes. Outro aspecto importante, foi que em 2015 houve redução de radiação solar em virtude da grande quantidade de dias nublados. Isso alterou o acúmulo de massa seca nas sementes formadas e, consequentemente a reduziu a produtividade.

\section{CONCLUSÃO}

Nos dois anos de monitoramento das condições físico-hídricas do Cambissolo Húmico para o cultivo do linho ficou evidente o bom fornecimento de água para a planta, com pequenas variações no armazenamento de água no solo decorrente das alterações meteorológicas ocorridas nos dois ambientes avaliados (ano de 2014 e 2015). Os períodos de menor conteúdo de água coincidiram com a primeira fase vegetativa do linho em ambas as variedades. No ambiente edafoclimático de 2015 o conteúdo de água no solo permaneceu acima da CAD com balanço hídrico registrando excessos de água no solo em, praticamente, todo o ciclo das plantas.

\section{AGRADECIMENTOS}

A Universidade Federal de santa Catarina, Campus de Curitibanos-SC, pelo apoio institucional.

\section{REFERÊNCIAS}

ALLEN , R. G.; PEREIRA, L. S.; RA ES, D.; SMITH, M. Crop evapotranspiration: Guide lines for computing crop water require ments. Rome: FAO, 1998. 300 p. (FAO - Irrigation and Dra inage Paper, 56).

ANDRADE, A.P.; MAFRA, A.L.;BALDO, G.R.; PICCOLLA, C. D.; BERTOL, I.; ALBUQUERQUE, J. A. Physical properties of a humic Cambisol under tillage and cropping systems after 12 years. Revista Brasileira de Ciência do Solo, v.34, n.1, p:219-226, jan/fev. 2010.

BASSEGIO, D.; SANTOS, R.F.; NOGUEIRA, C.E.C.; CATTANEO, A.J.; ROSSETTO, C. Manejo da irrigação na cultura da linhaça. Acta Iguazu, v.1, n.3, p. 98-107, 2012.

CARDUCCI, C.E.; OLIVERIA, G.C.; SEVERIANO, E.C.; ZEVIANI, W.M. Modelagem da curva de retenção de água de Latossolos utilizando a equação duplo van Genuchten. Revista Brasileira de Ciência do Solo, v. 35, n.1, jan./fev. p:77-86, 2011.

CASA, R.; RUSSELL, G.; LO CASCIO, B.; ROSSINI, F. Environmental effects on linseed (Linum usitatissimum L.) yield and growth of flax at different stand densities. European Journal of Agronomy, v.11, p: 267-278, 1999.

COLLARES, G. L.;REINERT,D. J.; REICHERT, J. M.; KAISER, D. R. Compactação de um latossolo induzida pelo tráfego de máquinas e sua relação com o crescimento e produtividade de feijão e trigo. Revista Brasileira de Ciência do Solo, v. 32, n. 3, p:933-942, mai./jun. 2008

COSMO, B. M. N.; CABRAL, A. C.; PINTO, L. P.; FRIGO, J. P.; AZEVEDO, K. D. de; BONASSA, G. Linhaça Linum asitatissimun, Suas Características. Revista Brasileira de Energias Renováveis, v. 3, n.3, p. 189196, jul./set. 2014.

COSTA, A.; ALBUQUERQUE, J. A.; COSTA, A.; PÉRTILE, P.; SILVA, F. R. Water retention and availability in soils of the state of Santa Catarinabrazil: effect of textural classes, soil classes and lithology. Revista Brasileira de Ciência do Solo, v.37, n. 6, p:1535-1548, nov/dez. 2013.

EMBRAPA - Empresa Brasileira de Pesquisa Agropecuária. Solos. Manual de métodos de análise de solo. 2. ed. revista. Rio de Janeiro: Embrapa Solos, 2011. $225 \mathrm{p}$.

EMBRAPA- Empresa Brasileira de Pesquisa Agropecuária. Solos. Sistema Brasileiro de Classificação de Solos., 3. ed. revista. Rio de Janeiro: Embrapa Solos, 2013. 412 p.

EMBRAPA - Empresa Brasileira de Pesquisa Agropecuária. Atlas climático da Região Sul do Brasil: Estados do Parana, Santa Catarina e Rio Grande do Sul. Editores técnicos: Wreg, M.S.; Steinmetz, S.; Reisser, J., C.; Almeida, I.R. Pelotas: Embrapa Clima Temperado; Colombo: Embrapa Florestas, 2011.

KOHN, L. S.; CARDUCCI, C. E.; SILVA, K. C. R.; BARBOSA, J. S.; FUCKS, J. S.; BENEVENUTE, P. A. N. Desenvolvimento das raízes de linho (Linum usitatissimum L.) em dois anos de cultivo sobre Cambissolo Húmico. Scientia Agraria, v. 17, n. 1, p: 36-41, jan/mar. 2016. Disponível em: http://revistas.ufpr.br/agraria/article/view/46191. Acesso em: 10 de outubro de 2016. 
MENEGASSE, L. N.; GONÇALVES, J. M.; FANTINEL, L. M. Disponibilidades hídricas na Província Cárstica de Arcos- Pains-Doresópolis. Alto São Francisco. Minas Gerais. Brasil. Revista Aguas Subterrâneas, v.16, n.1, p.1-19, 2002.

MOREIRA, N. B.; LIBARDI, P. L.; SALVADOR, M. M. S.; SOUSA, H. H. F. Análise espaço-temporal de componentes do balanço hídrico em um Latossolo. Revista Brasileira de Ciência do Solo, v. 38, n.1, p:60-72, já./ fev.2014.

OLIVEIRA, G.C.; DIAS JUNIOR, M. S.; RESCK, D.V.S.; CURI, N. Caracterização química e físicohídrica de um Latossolo Vermelho após vinte anos de Manejo e cultivo do solo. Revista Brasileira de Ciência do Solo, v. 28, n. 2, p. 327-336, mar./abril. 2004.

REICHERT, J. M.; ALBUQUERQUE, J. A.; GUBIANI, P. I.; KAISER, D. R.; MINELLA, J. P. G.; REINERT, D. J. Hidrologia do solo, disponibilidade de água às plantas e zoneamento agroclimático. In: FILHO, O. K.; MAFRA, A. L.; GATIBONI, L. C. (Eds.). Tópicos em Ciência do Solo. Viçosa: Sociedade Brasileira de Ciência do Solo, 2011, v. VII. p. 1-54.

REICHARDT, K.; TIM, L. C. Solo, planta e atmosfera: conceitos, processos e aplicações. Manoele: São Paulo, $2^{\mathrm{a}}$ ed., 2008, 478p.

SANTOS, H.G.; JACOMINE, P.K.T.; ANJOS, L.H.C.; OLIVEIRA, V.A.; LUMBRERAS, J.F.; COELHO, M.R.; ALMEIDA, J.A.; CUNHA, T.J.F.; OLIVEIRA, J.B. Sistema brasileiro de classificação de solos. 3. ed. Embrapa: Rio de Janeiro, 2013, 353 p.

SERAFIM, M. E.; OLIVEIRA, G.C.; LIMA, J.M.; SILVA, B.M.; ZEVIANI, W.M.; LIMA, V.M.P.

Disponibilidade hídrica e distinção de ambientes para cultivo de cafeeiros. Revista Brasileira de Engenharia Agricola e Ambiental, v.17, n.4, p.362-370, abril. 2013.

SILVA, E. A.; OLIVEIRA, G. C.; CARDUCCI, C.E.; SILVA, B. M.;OLIVEIRA, L. M.; COSTA, J.C. Doses crescentes de gesso agrícola, estabilidade de agregados e carbono orgânico em Latossolo do Cerrado sob Cafeicultura. Revista de Ciências Agrárias, v. 56, n. 1, p. 25-32, jan./mar. 2013.

SILVA, R. A. B.; LIMA, J.R.S.; ANTONINO, A. C.D.; GONDIM, P. S.S; SOUZA, E.S.; BARROS JÚNIOR, G. Balanço hídrico em Neossolo Regolítico cultivado com braquiária (Brachiaria decumbens Stapf). Revista Brasileira Ciência Solo, v. 38, n. 1, p:147157, jan./fev.2014.

SILVA, M.A.S.; MAFRA, A.L.; ALBUQUERQUE, J.A.; BAYER,C.; MIELNICZUK, J. Atributos físicos do solo relacionados ao armazenamento de água em um Argissolo Vermelho sob diferentes sistemas de preparo. Ciência Rural, v.35, n.3, p:544-552, mai./jun.2005.

THORNTHWAITE, C.W.; MATHER, J.R. The water balance. Centerton, NJ: Drexel Institute of Technology Laboratory of Climatology, 1955. 104p. (Publications in Climatology, vol. VIII, n.1). 